Buletin Ilmiah Mat. Stat. dan Terapannya (Bimaster)

Volume 09, No. 4 (2020), hal $559-566$.

\title{
PERBANDINGAN KINERJA PETA KENDALI DECISION ON BELIEF (DOB) DAN PETA KENDALI U PADA PRODUKSI CRUMB RUBBER
}

\author{
Maria Regina Vindasari, Helmi, Nurfitri Imro'ah
}

\begin{abstract}
INTISARI
Setiap perusahaan pasti menginginkan proses produksi yang terkendali. Terkait hal itu, pemilihan peta kendali sebagai alat pengendalian kualitas statistik merupakan keputusan yang penting. Umumnya produk yang dihasilkan sebuah perusahaan memiliki jumlah yang bervariasi setiap periodenya serta pengendalian kualitas yang dilakukan lebih sering menghitung kecacatan dari produk yang dihasilkan. Peta kendali yang sesuai pada kasus tersebut adalah peta kendali atribut. Peta kendali atribut adalah peta kendali yang digunakan apabila karakteristik yang digunakan bersifat cacat atau tidak cacat. Pada kasus ini, dapat dipilih peta kendali u karena jumlah produksi yang dihasilkan bervariasi dan cacat yang dihitung adalah jumlah cacat pada per satuan produk. Perkembangan peta kendali atribut yang semakin pesat memunculkan peta kendali baru yang dinamakan peta kendali Decision on Belief (DOB). Peta kendali ini dikatakan lebih cepat dalam melihat pergeseran data. Terkait hal itu, dilakukan perbandingan kinerja antara peta kendali DOB dan peta kendali u untuk menganalisis proses produksi crumb rubber pada PT. PQL. Penelitian dilakukan dengan terlebih dahulu membuat peta kendali u dan peta kendali DOB. Setelah itu dilakukan analisis perbandingan kinerja dari peta kendali DOB dan peta kendali at. Hasil dari penelitian ini dapat disimpulkan bahwa kinerja dari peta kendali DOB lebih cepat mendeteksi pergeseran data sehingga dapat meminimalisir kemungkinan terjadinya proses yang tidak terkendali.
\end{abstract}

Kata Kunci: Pengendalian kualitas statistik, Peta kendali u, Peta kendali DOB.

\section{PENDAHULUAN}

Globalisasi yang terjadi di Indonesia membuat banyak perusahaan berkembang sesuai dengan bidangnya masing-masing. Perkembangan perusahaan-perusahaan yang sangat pesat ini menimbulkan daya saing yang besar antar perusahaan. Saat ini, banyak perusahaan bersaing untuk memenangkan kompetisi menarik minat konsumen. Ada banyak cara perusahaan untuk menarik minat konsumen, salah satunya dengan memberikan perhatian penuh pada kualitas produk yang dihasilkan. Kualitas merupakan standar spesifikasi dari suatu perusahaan, tetapi tidak jarang suatu produk tidak memenuhi spesifikasi yang ditetapkan oleh perusahaan. Berdasarkan hal tersebut, diperlukan pengendalian kualitas statistik yang berguna untuk mengurangi produk di luar spesifikasi. Pengendalian kualitas statistik mempunyai alat-alat yang dapat membantu dalam mengendalikan keragaman suatu produk. Salah satu alat pengendalian tersebut adalah peta kendali. Peta kendali pertama kali diperkenalkan oleh Walter A. Shewhart yang digunakan untuk mengetahui apakah suatu proses telah terkendali atau belum. Peta kendali ini dikenal dengan nama peta kendali Shewhart. Menurut karakteristik kualitasnya, peta kendali Shewhart dibagi menjadi dua macam yaitu peta kendali variabel dan peta kendali atribut. Peta kendali variabel digunakan apabila karakteristik kualitasnya dapat diukur sedangkan peta kendali atribut digunakan apabila karakteristik kualitas yang digunakan hanya bersifat cacat atau tidak cacat [1].

Umumnya produk yang dihasilkan sebuah perusahaan memiliki jumlah yang bervariasi setiap periode serta pengendalian kualitas yang dilakukan lebih sering menghitung kecacatan dari produk yang dihasilkan. Terkait hal itu, dipilih peta kendali $u$ untuk mengendalikan proses tersebut. Peta kendali $u$ dipilih karena karakteristik kualitasnya atribut dan menggunakan sampel yang jumlahnya bervariasi dari setiap periode. Sebuah konsep peta kendali baru yang juga mengendalikan kualitas 
untuk data atribut yaitu peta kendali Decision on Belief (DOB). Peta kendali ini dikatakan lebih sensitif dalam melihat pergeseran data ke arah batas kendali sehingga lebih cepat mendeteksi adanya data yang tidak terkendali [2]. Terkait hal itu, peneliti ingin membandingkan kinerja peta kendali $u$ dan peta kendali DOB pada proses produksi salah satu perusahaan crumb rubber yang dengan alasan tertentu tidak bersedia disebutkan namanya. Selanjutnya digunakan sebutan perusahaan PQL. Crumb rubber merupakan karet kering yang diolah menjadi karet remah. Crumb rubber biasanya diolah menjadi lintasan atletik, bumper mobil, alas kaki mobil, dan lain-lain [3]. Hasil yang diperoleh dari penelitian ini diharapkan dapat membantu perusahaan untuk melakukan perbaikan kualitas dan membantu dalam menentukan peta kendali yang meminimalisir terjadinya data tidak terkontrol.

Penelitian ini membahas tentang bagaimana perbandingan kinerja peta kendali DOB dan peta kendali $u$ pada produksi crumb rubber di PT. PQL dengan tujuan penelitian yaitu untuk menganalisis perbandingan kinerja peta kendali DOB dan peta kendali $u$ pada produksi crumb rubber di PT.PQL. Penelitian ini dibatasi pada data yang digunakan adalah data hasil produksi dan data kecacatan crumb rubber pada tahun 2014 sampai tahun 2016 dan perbandingan kinerja peta kendali DOB dan peta kendali $u$ dilakukan dengan melihat pergeseran titik kearah batas kendali.

Langkah pertama dalam penelitian ini adalah mengumpulkan data. Setelah data terkumpul, maka dilakukan analisis deskriptif. Setelah itu, data diuji apakah data tersebut berdistribusi Poisson atau tidak. Jika data tidak berdistribusi Poisson maka data dapat dianalisis dengan peta kendali lain. Sedangkan jika data berdistribusi Poisson maka penelitian dapat dilanjutkan ke langkah selanjutnya yaitu dengan menghitung dan membuat peta kendali $u$ dan peta kendali DOB. Setelah peta kendali $u$ dan peta kendali DOB dibuat, dilakukan analisis perbandingan pada kedua peta kendali. Selanjutnya diperoleh peta kendali dengan kinerja yang terbaik untuk produksi crumb rubber di PT. PQL.

\section{PETA KENDALI}

Peta kendali merupakan alat pengendalian kualitas statistik yang berbentuk tampilan grafis dari karakteristik kualitas yang telah diukur atau dihitung dalam sampel sesuai dengan waktu atau observasinya. Peta kendali berisi garis tengah (GT) yang mewakili nilai rata-rata karakteristik kualitas yang sesuai dengan keadaan dalam kendali. Dua garis horizontal lainnya, yaitu pada bagian atas disebut dengan batas kendali atas (BKA) dan pada bagian bawah disebut batas kendali bawah (BKB) [1]. Jika ada titik yang keluar dari batas kendali maka dapat dikatakan bahwa proses produksi tidak terkendali dan jika semua titik berada di dalam batas kendali maka dikatakan proses produksi terkendali. Ilustrasi peta kendali dapat dilihat pada Gambar 1 berikut.

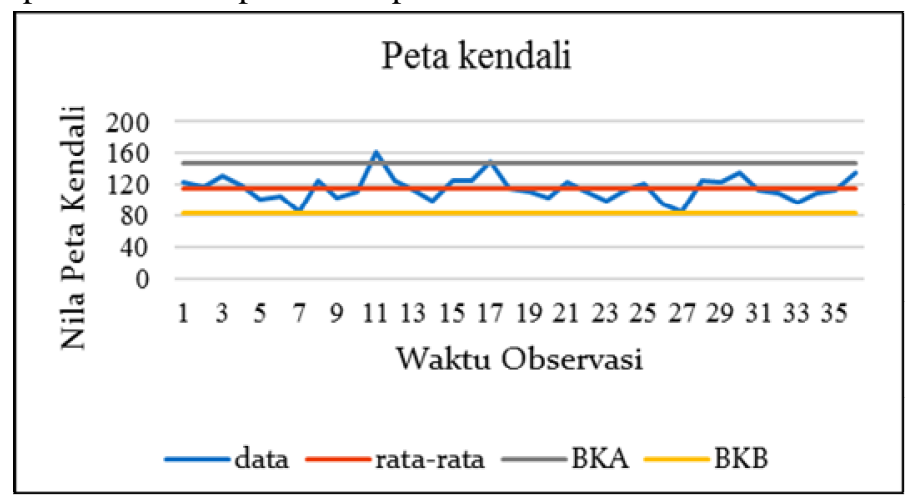

Gambar 1. Ilustrasi Peta Kendali

Model umum untuk peta kendali adalah misalkan $w$ merupakan sampel karakteristik kualitas dan diambil $\mu$ sebagai rata-rata dan $\sigma$ sebagai standar deviasi dari $w$. Kemudian GT, BKA dan BKB dinyatakan sebagai berikut [2]:

$$
\begin{aligned}
& G T=\mu_{w} \\
& B K A=\mu_{w}+L \sigma_{w}
\end{aligned}
$$




$$
B K B=\mu_{w}-L \sigma_{w}
$$

dimana $L$ adalah jarak dari garis tengah. Peta kendali yang dikembangkan menurut asas-asas ini dinamakan peta kendali Shewhart.

Peta kendali Shewhart ini dibagi menjadi dua bagian, yaitu peta kendali variabel dan peta kendali atribut. Peta kendali variabel adalah peta kendali yang digunakan untuk data kualitas yang dapat diukur seperti dimensi, berat, dan volume. Contoh peta kendali variabel adalah peta kendali $\bar{x}$ dan $R, \bar{x}$ dan 5 , dan peta kendali I-MR. Sedangkan peta kendali atribut adalah peta kendali yang digunakan untuk data karakteristik kualitas yang tidak diukur dengan skala numerik. Contoh peta kendali atribut ini adalah peta kendali $p, n p, u$, dan peta kendali $c$ [4].

\section{PETA KENDALI U}

Peta kendali $u$ merupakan salah satu peta kendali Shewhart yang karakteristiknya atribut. Peta kendali ini digunakan untuk mengendalikan proses produksi yang karakteristik kualitasnya diukur dari banyaknya ketidaksesuaian per unit produk yang dihasilkan. Peta kendali $u$ digunakan apabila jumlah sampel yang digunakan bervariasi dari waktu ke waktu. Berikut langkah-langkah membuat peta kendali $u[2]$ :

Hitung nilai statistik peta kendali $u$

Batas-batas kendali untuk peta kendali $u$

$$
u_{t}-\frac{x_{i}}{n_{i}}
$$

$$
\begin{gathered}
G T=\bar{u}=\frac{\sum_{i=1}^{m} x_{1}}{\sum_{i=1}^{m} n_{i}} \\
B K A=\bar{u}+3 \sqrt{\frac{\bar{u}}{n_{i}}} \\
B K B=\bar{u}-3 \sqrt{\frac{\bar{u}}{n_{i}}}
\end{gathered}
$$

dimana $u_{i}$ adalah nilai statistik peta kendali $u$ pada waktu ke- $i$ dan $x_{i}$ merupakan jumlah cacat pada waktu ke- $i$ serta $n_{i}$ merupakan jumlah produksi pada waktu ke- $i$. Jika $n_{i}$ bernilai 0 maka perhitungan dapat dilanjutkan pada waktu produksi yang jumlah produksinya bernilai.

\section{PETA KENDALI DOB}

Peta kendali DOB merupakan peta kendali yang digunakan untuk mengendalikan data pengamatan tunggal yang karakteristiknya atribut. Misalkan $\boldsymbol{O}_{i}=\left(x_{1}, x_{2}, x_{3}, \ldots, x_{n}\right)$ menjadi vektor pengamatan pada $i$ iterasi, dimana $x$ adalah pengamatan jumlah ketidaksesuaian pada produk yang diteliti. Asumsikan $B\left(\boldsymbol{x}_{i}, \boldsymbol{o}_{i-1}\right)$ sebagai proses yang berada dalam keadaan in-control. Pengukuran ini merupakan probabilitas yang akan berada di dalam keadaan in-control berdasarkan vektor pengamatan yang diperoleh sampai pada iterasi ke $(i-1)$ dan pengamatan yang diperoleh di iterasi ke- $i$. Jika dimisalkan $B\left(x_{i}, \boldsymbol{O}_{i-1}\right)=B\left(x_{i-1}, \boldsymbol{O}_{i-2}\right)$ dalam keadaan in-control maka untuk memperbaharui tanggapan dalam iterasi pada keadaan optimum didefinisikan sebagai berikut [5]:

$$
\begin{aligned}
B\left(x_{i}, o_{i-1}\right) & =B\left(o_{i}\right) \\
& -\frac{B\left(O_{i-1}\right) \exp \left(\frac{x_{i}-\mu_{0}}{\sigma_{3}}\right)}{B\left(O_{i-1}\right) \exp \left(\frac{x_{i}-\mu_{0}}{\sigma_{0}}\right)+\left(1-B\left(O_{i-1}\right)\right)}
\end{aligned}
$$

dari Persamaan (8) dibentuk persamaan statistik baru $Z_{i}$ yaitu,

$$
Z_{i}=\frac{B\left(x_{i}, o_{i-1}\right)}{1-B\left(x_{i}, O_{i-1}\right)}=\frac{B\left(o_{i}\right)}{1-B\left(O_{i}\right)}
$$


Kemudian substitusikan Persamaan (8) ke Persamaan (9) sehingga diperoleh,

$$
\begin{aligned}
& Z_{i}= \frac{B\left(o_{i-1}\right) \exp \left(\frac{x_{i}-\mu_{0}}{a_{0}}\right)}{B\left(o_{i-1}\right) \exp \left(\frac{x_{i}-\mu_{0}}{\sigma_{0}}\right)+\left(1-B\left(o_{i-1}\right)\right)} \\
& 1-\frac{B\left(o_{i-1}\right) \exp \left(\frac{x_{i}-\mu_{0}}{\sigma_{0}}\right)}{B\left(o_{i-1}\right) \exp \left(\frac{x_{i}-\mu_{0}}{\sigma_{0}}\right)+\left(1-B\left(o_{i-1}\right)\right.} \\
& Z_{i}=\frac{B\left(o_{i-1}\right) \exp \left(\frac{x_{i}-\mu_{0}}{\sigma_{0}}\right)}{1-B\left(o_{i-1}\right)}
\end{aligned}
$$

dari Persamaan (9) diketahui bahwa $Z_{i}=\frac{B\left(o_{i}\right)}{1-E\left(o_{i}\right)}$, sehingga untuk $i-1$ diperoleh $Z_{i-1}=\frac{B\left(a_{i-2}\right)}{1-B\left(o_{i}-1\right)}$. Dengan demikian Persamaan (10) menjadi,

$$
Z_{i}=\exp \left(\frac{x_{i}-\mu_{c}}{\sigma_{0}}\right) Z_{i-1}
$$

dari Persamaan (11) dapat dijabarkan sebagai berikut,

$$
\begin{aligned}
& Z_{i}=\exp \left(\frac{x_{i}-\mu_{0}}{\sigma_{0}}\right) Z_{i-1} \\
& =\exp \left(\begin{array}{c}
x_{i}-\mu_{\mathbb{Q}} \\
\sigma_{\mathbb{Q}}
\end{array}\right)\left[\exp \left(\begin{array}{c}
x_{i}-\mu_{0} \\
\sigma_{\mathbb{Q}}
\end{array}\right) Z_{i-2}\right] \\
& =\exp \left(\frac{n_{1}-\mu_{2}}{\sigma_{2}}\right) \cdot \exp \left(\frac{\sigma_{i}-\mu_{0}}{\sigma_{2}}\right) \ldots\left[\exp \left(\frac{x_{i}-\mu_{2}}{\sigma_{0}}\right) Z_{i-i}\right] \\
& =\exp \left(\frac{x_{i}-\mu_{\mathbb{V}}}{\sigma_{2}}+\frac{x_{i-1}-\mu_{\mathbb{Q}}}{\sigma_{2}}+\cdots+\frac{x_{1}-\mu_{0}}{\sigma_{2}}\right) Z_{0} \\
& Z_{i}=\exp \left(\frac{\sum_{j=2}^{i} x_{j} j-i \mu_{0}}{\sigma_{a}}\right)
\end{aligned}
$$

Jika diberikan $i=1$ pada Persamaan (12) maka diperoleh,

$$
Z_{1}=\exp \left(\frac{\left(\tau_{j=1}^{i} x_{i j}\right)-i \mu_{2}}{\sigma_{2}}\right)=\exp \left(\frac{\left(\alpha_{1}-\mu_{2}\right]}{\sigma_{2}}\right)
$$

dan jika Persamaan (11) juga diberikan $i=1$ maka diperoleh,

$$
Z_{1}=\exp \left(\frac{\left(x_{1}-\mu_{0}\right)}{\sigma_{0}}\right) Z_{0}
$$

Dilihat dari Persamaan (13) dan Persamaan (14) dapat diketahui bahwa nilai $Z_{y}=1$. Jika nilai $Z_{v}=1$ disubstitusikan ke Persamaan (9) maka didapatkan nilai awal $B\left(\boldsymbol{O}_{0}\right)=0,5$.

Setelah itu Persamaan (12) disederhanakan menjadi,

$$
\ln \left(Z_{i}\right)=\frac{\left(\Gamma_{j=1}^{i} x_{j}\right)-i \mu_{0}}{\sigma_{0}}
$$

bentuk Persamaan (15) mengikuti bentuk distribusi normal baku yang memiliki nilai rata-rata 0 dan variansnya adalah $i$, dengan demikian $\ln \left(Z_{i}\right) \sim N(0, i)$. Kemudian dari Persamaan (15) dapat diperoleh BKB dan BKA untuk $\ln \left(Z_{i}\right)$ dengan menggunakan model peta kendali Shewhart yang ditunjukkan pada Persamaan (2) dan Persamaan (3). Maka nilai BKB dan BKA untuk $i n\left(Z_{i}\right)$ adalah sebagai berikut,

$$
\begin{aligned}
B K B_{\ln \left(z_{i}\right)} & =-k \sqrt{i} \\
B K A_{\ln \left(\sigma_{i}\right)} & =k \sqrt{i}
\end{aligned}
$$

dimana $k$ merupakan kelipatan standar deviasi dari $m\left(Z_{i}\right)$ dan ditentukan. Jika diasumsikan $\boldsymbol{O}_{i}=\left(x_{1}, x_{2}, x_{3}, \ldots, x_{n}\right)$ variabel acak berdistribusi normal, maka nilai $k=1,5$ [5].

Jika diberikan kesalahan tipe I $(\alpha)$, maka diperoleh

$$
P\left(-k \sqrt{l} \leq \ln \left(Z_{i}\right) \leq k \sqrt{i}\right)=1-\alpha
$$

Selanjutnya substitusikan nilai $Z_{i}$ dari Persamaan (9) ke Persamaan (16) sehingga diperoleh,

$$
P\left(-k \sqrt{i} \leq \ln \left(\frac{B\left(x_{i}, O_{i-1}\right)}{1-B\left(x_{i}, O_{i-1}\right)}\right) \leq k \sqrt{i}\right)=1-\alpha
$$


atau

$$
P\left(\exp (-k \sqrt{i}) \leq\left(\frac{B\left(x_{i}, O_{i-1}\right)}{1-B\left(x_{i}, O_{i-1}\right)}\right) \leq \exp (k \sqrt{i})\right)=1-\alpha
$$

Sehingga selang kepercayaan $100(1-\alpha) \%$ untuk $B\left(x_{i}, \boldsymbol{O}_{i-1}\right)$ adalah,

$$
\left(\frac{\exp (-k \sqrt{i})}{\exp (-k \sqrt{i})+1} \leq B\left(x_{i}, 0_{i-1}\right) \leq \frac{\exp (k \sqrt{i})}{\exp (k \sqrt{i})+1}\right)
$$

Kemudian dari Persamaan (17) diperoleh BKB untuk $B\left(x_{i}, \boldsymbol{O}_{i-1}\right)$ yaitu,

$$
B K B_{\left(a\left[k_{i}, 0_{i-1}\right)\right.}=\frac{\exp (-k \sqrt{i})}{\operatorname{sxp}(-k \sqrt{i})+1}
$$

dan BKA untuk $B\left(x_{i}, \boldsymbol{O}_{i-1}\right)$ yaitu,

$$
B K A\left(B\left(x, o_{i-1}\right)\right)=\frac{\exp (k \sqrt{i})}{\exp (k \sqrt{i})+1}
$$

\section{HASIL DAN PEMBAHASAN}

Data yang digunakan pada penelitian ini adalah jumlah keseluruhan cacat produk crumb rubber di PT. PQL dari tahun 2014 sampai 2016. Data cacat diambil dari sebuah penelitian yang menganalisis tentang metode Statistical Quality Control pada produksi crumb rubber. Selanjutnya, dilakukan analisis statistik deskriptif yang dapat dilihat pada Tabel 1.

Tabel 1. Hasil Analisis Statistik Deskriptif Jumlah Cacat

\begin{tabular}{cccccc}
\hline Rata-rata & Standar Deviasi & Minimum & Maksimum & Jumlah & $\mathrm{N}$ \\
\hline 115,861 & 15,892 & 85 & 162 & 4.171 & 36 \\
\hline
\end{tabular}

Setelah dilakukan analisis deskriptif pada data, selanjutnya dilakukan pengujian distribusi Poisson pada data. Hal ini dilakukan untuk mengetahui apakah data cacat crumb rubber memenuhi syarat distribusi Poisson atau tidak. Pengujian dilakukan menggunakan uji Kolmogorov-Smirnov. Hipotesis yang digunakan adalah sebagai berikut:

$H_{0}$ : Data crumb rubber berdistribusi Poisson

$H_{1}$ : Data crumb rubber tidak berdistribusi Poisson

Kriteria pengambilan keputusan pada uji Kolmogorov-Smirnov adalah $H_{\Omega}$ diterima jika nilai Asymp Sig $(2$ tailed $)>a(0,05)$.

Tabel 2. Hasil Uji Kolmogorov-Smirnov

\begin{tabular}{lr}
\hline & Nilai \\
\hline Jumlah Observasi & 36 \\
Asymp Sig $(2$ tailed $)$ & 0,779 \\
\hline
\end{tabular}

Tabel 2 menunjukkan bahwa nilai Asymp Sig (2 tailed) $>a(0,05)$ sehingga dapat disimpulkan bahwa $H_{0}$ diterima yang artinya data crumb rubber berdistribusi Poisson. Jika data crumb rubber berdistribusi Poisson maka langkah selanjutnya yaitu pembentukan peta kendali $u$ dan peta kendali DOB.

\section{Penerapan Peta Kendali u}

Langkah-langkah untuk membuat peta kendali $u$ diawali dengan mencari nilai statistik peta kendali $u$ menggunakan Persamaan (4). Perhitungan dilakukan sebagai berikut:

Bulan ke-1: $u_{1}=\frac{123}{45.350}=0,002654$

Bulan ke-2: $u_{2}=\frac{117}{42.962}=0,002723$

;

Bulan ke-36: $u_{36}=\frac{135}{41.728}=0,003235$ 
Setelah diperoleh nilai $u_{i}$, langkah selanjutnya adalah menentukan garis tengah ( $\bar{u}$ ) menggunakan Persamaan (5) dengan perhitungan sebagai berikut:

$\bar{u}=\frac{\sum_{i=1}^{36} x_{i}}{\sum_{i=1}^{36} n_{i}}==\frac{4.171}{1.440 .137}=0,002896$

Langkah selanjutnya adalah menghitung nilai BKA menggunakan Persamaan (6) dengan perhitungan sebagai berikut:

Bulan ke-1: $B K A=\bar{u}+3 \sqrt{\frac{\bar{u}}{n_{\mathrm{i}}}}=0,002896+3 \sqrt{\frac{0,002896}{46.350}}=0,003646$

Bulan ke-2: $B K A=\bar{u}+3 \sqrt{\frac{\bar{u}}{m_{i}}}=0,002896+3 \sqrt{\frac{0,002896}{42,962}}=0,003675$

;

Bulan ke-36: $B K A=\bar{u}+3 \sqrt{\frac{\bar{u}}{n_{i}}}=0,002896+3 \sqrt{\frac{0,002996}{41.728}}=0,003687$

Selanjutnya dihitung nilai BKB menggunakan Persamaan (7). Perhitungan nilai BKA adalah sebagai berikut:

Bulan ke-1: $B K B=\bar{u}-3 \sqrt{\frac{\bar{u}}{m_{i}}}=0,002896-3 \sqrt{\frac{0,002896}{46,350}}=0,002146$

Bulan ke-2: $B K B=\bar{u}-3 \sqrt{\frac{\bar{u}}{n_{i}}}=0,002896-3 \sqrt{\frac{0,002896}{42.962}}=0,002117$

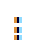

Bulan ke-36: $B K B=\bar{u}-3 \sqrt{\frac{\bar{u}}{n_{i}}}=0,002896-3 \sqrt{\frac{0,002896}{41.728}}=0,002106$

Setelah semua nilai diperoleh, tahap selanjutnya adalah membuat grafik peta kendali. Peta kendali $u$ ditunjukkan pada Gambar 2.

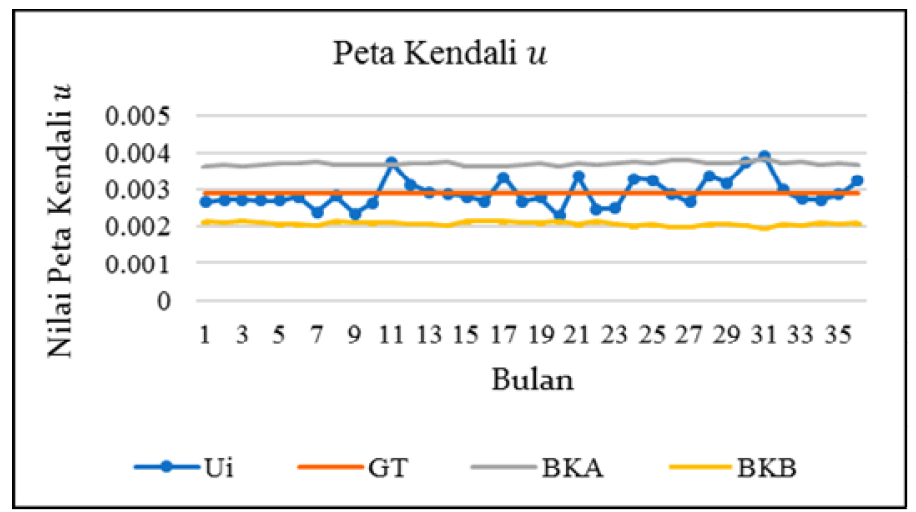

Gambar 2. Peta Kendali $u$

Berdasarkan Gambar 2, dapat diketahui bahwa terdapat 2 titik yang keluar dari batas kendali yaitu titik ke-11 dan titik-31 sehingga dapat dikatakan bahwa produksi crumb rubber belum terkendali secara statistik. Perusahaan diharapkan melakukan perbaikan kualitas pada produksi crumb rubber.

\section{Penerapan Peta Kendali DOB}

Langkah-langkah untuk membuat peta kendali DOB diawali dengan mencari nilai dari $B\left(\boldsymbol{O}_{i}\right)$. Nilai ini didapatkan dari Persamaan (8) dan dibutuhkan untuk mencari nilai $B\left(\boldsymbol{O}_{1}\right)$ sampai seterusnya hingga mendapatkan nilai $B\left(O_{36}\right)$. Maka dari itu titik-titik dalam peta kendali DOB tidak dapat dihilangkan saat terjadi out of control karena saling berkaitan. Diketahui nilai $B\left(\boldsymbol{O}_{0}\right)$ adalah 0,5 menjadi titik pengamatan awal. Kemudian untuk perhitungan $B\left(\boldsymbol{O}_{1}\right)$ sampai dengan $\boldsymbol{B}\left(\boldsymbol{O}_{36}\right)$ adalah sebagai berikut, 


$$
\begin{aligned}
& B\left(O_{1}\right)=\frac{(0.5) \exp \left(\frac{123-115,86}{10,76}\right)}{(0,5) \exp \left(\frac{173-115,86}{10,76}\right)+(1-0,5)}=0,659985 \\
& B\left(O_{2}\right)=\frac{(0.659985) \exp \left(\frac{117-115,86}{10,76}\right)}{(0,659985) \exp \left(\frac{117-115,86}{10,76}\right)+(1-0,659985)}=0,683312 \\
& B\left(O_{3 e}\right)=\frac{(0,144542) \exp \left(\frac{135-115,86}{10,76}\right)}{(0,141542) \exp \left(\frac{135-115,86}{10,76}\right)+(1-0,141542)}=0,5
\end{aligned}
$$

Setelah diperoleh nilai $\boldsymbol{S}\left(\boldsymbol{O}_{i}\right)$, langkah selanjutnya adalah menentukan nilai BKA menggunakan Persamaan (19). Perhitungan BKA sebagai berikut:

$$
\begin{aligned}
& B K A_{\left(a\left(x_{1}, O_{2}\right)\right.}=\frac{\exp (k \sqrt{i})}{\exp (k \sqrt{i})+1}=\frac{\exp (1,5 \sqrt{1})}{\exp (1,5 \sqrt{1})+1}=0,817574 \\
& B K A_{\left(a\left(x_{2}, 0_{1}\right)\right.}=\frac{\exp (k \sqrt{i})}{\exp (k \sqrt{i})+1}=\frac{\exp (1,5 \sqrt{2})}{\exp (1,5 \sqrt{2})+1}=0,892958 \\
& B K A_{\left(B\left(x_{3}, 0_{3}, 3\right)\right.}=\frac{\exp (k \sqrt{i})}{\exp (k \sqrt{i})+1}=\frac{\exp (1,5 \sqrt{36})}{\exp (1,5 \sqrt{36})+1}=0,999877
\end{aligned}
$$

Kemudian dilakukan perhitungan untuk nilai BKB berdasarkan Persamaan (18), perhitungan nilai BKB adalah sebagai berikut:

$$
\begin{aligned}
& B K B_{\left(a\left(N_{1}, 0_{2}\right)\right.}=\frac{\exp (-k \sqrt{i})}{\exp (-k \sqrt{i})+1}=\frac{\exp (-1,5 \sqrt{1})}{\exp (-1,5 \sqrt{1})+1}=0,182426 \\
& B K B_{\left(2\left(x_{2}, a_{1}\right)\right.}=\frac{\exp (-k \sqrt{i})}{\exp (-k \sqrt{2})+1}=\frac{\exp (-1,5 \sqrt{2})}{\exp (-1,5 \sqrt{2})+1}=0,107042 \\
& \text {; } \\
& B K B_{\left(2\left(m_{3}, 0_{3}\right]\right)}=\frac{\exp (-k \sqrt{i})}{\exp (-k \sqrt{i})+1}=\frac{\exp (-1,5 \sqrt{36})}{\exp (-1,5 \sqrt{36})+1}=0,000123
\end{aligned}
$$

Setelah semua nilai diperoleh, tahap selanjutnya adalah membuat grafik peta kendali. Peta kendali DOB ditunjukkan pada Gambar 3.

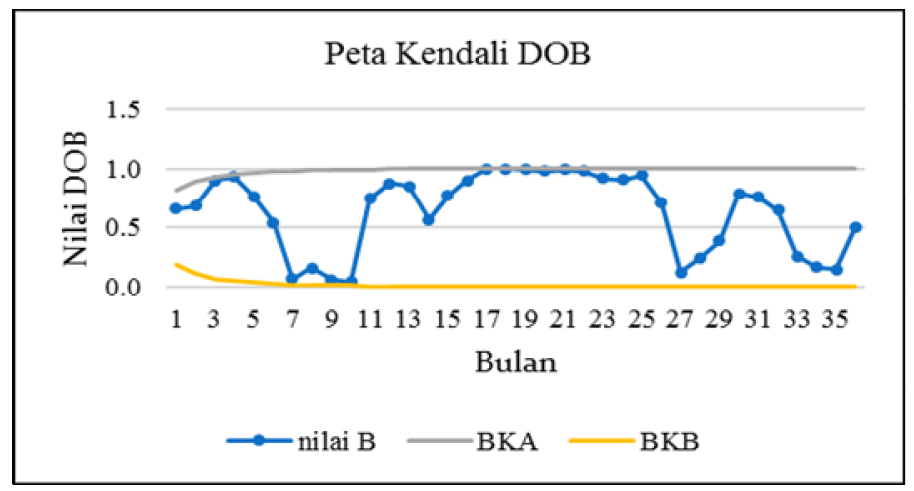

Gambar 3. Peta Kendali DOB

Berdasarkan Gambar 3, dapat dilihat bahwa pengendalian kualitas pada produksi crumb rubber dengan peta kendali DOB sudah terkendali, akan tetapi banyak titik-titik yang hampir keluar dari batas kendali atas maupun bawah. Titik-titik yang hampir keluar dari batas kendali ini harus diwaspadai oleh perusahaan. Pergeseran titik-titik kearah batas kendali sudah terlihat dari bulan awal observasi yaitu bulan ke-3. Perusahaan dapat mulai memperbaiki kualitas produksi dari bulan ke-3 tersebut agar di bulan selanjutnya tidak ada titik yang mendekati atau keluar dari batas kendali. 


\section{Perbandingan Kinerja Peta Kendali DOB dan Peta Kendali $u$}

Setelah diperoleh peta kendali DOB dan peta kendali $u$, langkah selanjutnya adalah membandingkan kinerja peta kendali DOB dan peta kendali $u$ dengan melihat pergeseran data kearah batas kendali. Perbandingan peta kendali DOB dan peta kendali $u$ dapat dilihat pada Tabel 3 .

Tabel 3. Perbandingan Kinerja Peta Kendali

\begin{tabular}{ccc}
\hline Peta Kendali & $\begin{array}{c}\text { Jumlah Data yang Tidak } \\
\text { Terkontrol }\end{array}$ & $\begin{array}{c}\text { Pergeseran Data ke Arah Batas } \\
\text { Kendali Dimulai pada }\end{array}$ \\
\hline Peta kendali $\boldsymbol{u}$ & 2 & Titik ke-10 \\
\hline Peta Kendali DOB & 0 & Titik ke-3 \\
\hline
\end{tabular}

Berdasarkan Tabel 3, dapat dilihat pada peta kendali $u$ terdapat 2 titik yang keluar dari batas kendali yaitu titik ke-11 dan ke-31 sehingga dapat dikatakan bahwa produksi crumb rubber belum terkendali secara statistik atau proses produksi crumb rubber kurang baik. Sedangkan pada peta kendali DOB tidak ada titik yang keluar dari batas kendali. Akan tetapi, pergeseran data ke arah batas kendali sudah terlihat pada titik awal. Hal ini menunjukkan bahwa peta kendali DOB lebih cepat dalam melihat pergeseran data dan dapat mendeteksinya lebih awal sehingga dapat meminimalisir kemungkinan terjadinya proses yang tidak terkendali. Dengan demikian, kinerja peta kendali DOB dapat dikatakan lebih tepat dalam proses pengendalian kualitas produksi crumb rubber.

\section{PENUTUP}

Berdasarkan hasil analisis perbandingan kinerja peta kendali DOB dan peta kendali $u$ pada produksi crumb rubber di PT. PQL, dapat disimpulkan bahwa kinerja peta kendali DOB lebih baik dibandingkan peta kendali $u$. Walaupun pada peta kendali DOB tidak terdapat titik yang berada diluar batas kendali, tetapi peta kendali DOB lebih cepat dalam membaca pergeseran data ke arah batas kendali dan dapat mendeteksinya lebih awal sehingga dapat meminimalisir kemungkinan terjadinya proses yang tidak terkendali. Jadi perusahaan lebih dapat mencegah proses yang tidak terkendali dengan melakukan pengawasan serta perbaikan dari lima faktor yang utama, yaitu faktor manusia, mesin, metode, material, dan lingkungan.

\section{DAFTAR PUSTAKA}

[1]. Montgomery, D., 2009, Introduction to Statistical Quality Control, Ed ke-6, John Wiley \& Sons, United States of America.

[2]. Fuady, A.Z. dan Mashuri, M., 2014, Pengendalian Kualitas Produksi Botol RC Cola 200 ML di PT. IGLAS (Persero) Gresik Menggunakan Diagram Kontrol DOB (Decision On Belief), Jurnal Sains dan Seni POMITS, 3:D-254-D-259

[3]. Robiansyah; Kusnandar, D. dan Imro'ah, N., 2018, Analisis Pengendalian Kualitas Produksi Crumb Rubber Dengan Metode Statistical Quality Control, Buletin Ilmiah Math, Stat, dan Terapannya (Bimaster), 7:93-100

[4]. Syukron, A. dan Kholil, M., 2013, Six Sigma Quality for Business Improvement, Graha Ilmu, Yogyakarta.

[5]. Nehzad, M.S.F. dan Niaki, S.T.A, 2010, A New Monitoring Design for Uni-Variate Statistical Quality Control Charts, Information Sains, 180:1051-1059
MARIA REGINA VINDASARI
: Jurusan Matematika FMIPA UNTAN, Pontianak mariareginavindasari@gmail.com
HELMI
: Jurusan Matematika FMIPA UNTAN, Pontianak helmi@ math.untan.ac.id
NURFITRI IMRO’AH
: Jurusan Matematika FMIPA UNTAN, Pontianak nurfitriimroah@math.untan.ac.id 